\title{
The Current Situation, Problems and Countermeasure Research of Chain-management Development in China
}

\author{
Li Hongyun; Hou Yu; Han Yu; Ning Yunxia \\ Department of Marketing, Shijiazhuang Information Engineering Vocational College, Shijiazhuang Hebei 050035
}

\begin{abstract}
At present, Chinese Chain-management, which is still at the initial stage of development, is in obvious disadvantage in the competition with foreign large-scale chain enterprises. Merger, franchise and some other approaches should be adopted by Chinese chain enterprises in order to broad in scale. Furthermore, more attention should be paid to informatization system, constant optimization and upgrade information system. By choosing good promotion and advertising modes to increase customer's awareness to chain enterprises brand, we could smoothly implement the chain enterprise brand strategy. Finally, chain enterprise management in China will expand under the context of new market.
\end{abstract}

Keywords: chain management; development; brand strategy; logistics informatization

In the field of circulation, retail industry, catering industry, service industry, and so on run the same industry or business form, organizing common shopping and franchise. These industries engage in businesses under the same business image, and share scale merit. This kind of business operation organization form is referred to as "chain management". Currently, although chain management in China has a relatively fast development, many issues still exist. The important mission for chain management in China is about how to grasp the current opportunity, give full play to chain management, establish long-term development strategy, and has fast development within standard, so as to expand the scale constantly and take an advanced status in the intense competition, especially in the competition with foreign enterprises.

\section{The Current Situation of China's Chain Management}

After years of development, China's chain management is no longer as it has been. According to the objective requirements of China's national conditions and the development of chain management, a lot of characteristics present.

\subsection{Diversification of Business Form}

Business form is aiming at the specific needs of customers and a certain amount of strategy goal to utilize the commodity business structure selectively, the site, scale, form of a store, price policy, sales modes and service, with the purpose to offer service forms of sales and service categorization. Based on this definition, we could classify chain business form into convenience store(CVS), discount store, supermarket, large supermarket, monopoly store, Sam's club, and direct sales from factory and so on. The diversification of business form is the coexistence, development and competition of multiple business forms, as well as the manifestation of economic development and intensified service.

From table 1, we know that China's chain enterprises include convenience store, discount store, supermarket, large supermarket, club, monopoly store and other kinds business forms, among which the numbers of supermarket are at most. Supermarket sales in 2008 increased its year-on-year growth by $17.19 \%$, whereas the year-on-year growth of convenience store is $19.12 \%$, discount store $27.47 \%$, large supermarket $19.35 \%$, Sam's club $17.05 \%$, and monopoly store $25.79 \%$, home building materials store $6.27 \%$, and a direct sales store $20.86 \%$. Viewing from operation scale and employees, Supermarket is the main business form in China's chain management. Supermarket and large supermarket own relatively more employees and larger business areas, but have a relatively lower sales increase. Compared with supermarket, discount store and monopoly store have a higher sales increase and they are promising business forms among chain management. Home building materials store and factory direct selling have lesser sales, resulting in a relatively slow development.

\subsection{Spreading in Different Parts of China, China's Chain Enterprises have Dispropor- tional Development}

The disproportional developments of China's chain enterprises are due to the development imbalance of China's eastern and western areas. Eastern area has good infrastructure, dense population, and higher industrialization and urbanization, whereas middle and western China are poorly equipped with facilities due to late construction and development. Therefore, the development of middle and western China's chain enter- 
Table 1. Basic Situation of China's Chain Enterprises Divided by Business Form

\begin{tabular}{cccccc}
\hline \multicolumn{2}{c}{ Quantity of stores(unit) } & \multicolumn{2}{c}{$\begin{array}{c}\text { Numbers of employees } \\
\text { (ten thousand) }\end{array}$} & \multicolumn{2}{c}{$\begin{array}{c}\text { Sales amount } \\
\text { (hundred million Yuan) }\end{array}$} \\
2007 & 2008 & 2007 & 2008 & 2007 & 2008 \\
\hline 151694 & 168502 & 174.70 & 197.08 & 16931.5 & 20466.5 \\
13912 & 16196 & 927.00 & 9.79 & 231.7 & 276.0 \\
628 & 784 & 74.00 & 0.94 & 27.3 & 34.8 \\
27145 & 30240 & 37.56 & 41.97 & 1919.5 & 2249.5 \\
7332 & 8072 & 30.53 & 35.82 & 1871.7 & 2233.8 \\
324 & 331 & 1.21 & 1.31 & 139.0 & 162.7 \\
13047 & 14651 & 10.89 & 12.42 & 884.5 & 1112.7 \\
93 & 116 & 1.04 & 1.22 & 79.7 & 84.7 \\
46 & 50 & 0.04 & $4.00 \%$ & 11.5 & 13.9 \\
\hline
\end{tabular}

Table 2. Basic Situation of Chain Enterprises of Eastern and Western China

\begin{tabular}{ccccc}
\hline Region & $\begin{array}{c}\text { Numbers of } \\
\text { stores(unit) }\end{array}$ & $\begin{array}{c}\text { Business areas (thousands } \\
\text { of square meters) }\end{array}$ & $\begin{array}{c}\text { Employees } \\
\text { (ten thousand) }\end{array}$ & $\begin{array}{c}\text { Sales amount (hundred } \\
\text { million Yuan) }\end{array}$ \\
\hline Eastern China & 104899 & 7219.7 & 134.75 & 15061 \\
$\begin{array}{c}\text { China's Central } \\
\text { Region }\end{array}$ & 29855 & 1716.43 & 31.68 & 2819 \\
Western China & 33748 & 1261.8 & 24.86 & 2135 \\
\hline
\end{tabular}

prises are inferior compared with chain enterprises of eastern China. As shown from table 2 .

From table 2, it is observed that the numbers and areas of stores, numbers of employees, as well as sales amount of eastern China are in a dominate position compared with western and central part of China. Forms this kind of aspect is the historical reason and the objective restrictions. Meanwhile, it is shown that the markets of China's central and western area have not been fully developed. Therefore, at the time of implementing develop-the-west strategy, chain enterprises have development potentials in both central and western China.

\subsection{Faster Development of China's Chain Management}

In recent years, China's economy is developing rapidly with the acceleration of urbanization, migration of villagers to the cities, and the increase of city's scale and population. People's income and consumption level are thus increasing. Chain enterprises make a quick development, using the main sales target as the vast number of customers.

\subsection{Chain Management Develop to a Variety of Industries}

Not only food and daily necessities employ chain management modes, culture and sports supplies, cars, motorcycles, household appliances, and electronics also adopt this kind of management mode. For example, GOME electric appliances and Suning electronics are representatives of household appliances, McDonald's, KFC and Little Sheep Restaurant are representatives of catering industry. Easyhome and HOBA home furnishings represent household industry.

\section{The Existing Problems in China's Chain Management}

\subsection{Lots of Chain Enterprises do not have a Well-established Logistics Distribution Center}

By means of certain linkage, chain management connects various scattered and isolated business units and operates according to the fixed rules. In order to achieve enterprise scale, refined management, effective operation, and strengthened competiveness, China's chain enterprises should establish a logistics management system which is compatible with the current status of chain enterprises. Distribution center is a logistic base of chain management. From the wide view of big foreign chain enterprises, their achievements cannot be separated from a phenomenal and efficient logistics system. The success of Wal-Mart lies in the low prices of commodities and the scale. Besides, there is a powerful and effective logistics system. By this powerful distribution capability, Wal-Mart has integrated manufacturers and logistics providers into its own management network. Therefore, commodity movement from factory to store could be done within the shortest time and the lowest costs. The high efficiency and accuracy of Wal-Mart's logistics and distribution make a lot of competitors humbled. This is why Wal-Mart could expand gradually. Reduction of circulation links by centralized distribution and transaction costs in order to maximize the profit is not only the key to Wal-Mart's success but also the goal for 
most China's enterprises. At present, some of China's chain enterprises cannot form an effective economy of scale, and lower the cost to the max under the current situation.

\subsection{Negative Brand Image Lacks of Culture Content}

A good brand is the base and soul of chain management. Excellent chain enterprises all own a well-known and reputable brand. A great number of big international chain enterprises who build and boost the popularity of their brand by a series of marketing activities, innovation of enterprise management, differentiation and individuation have stronger brand awareness. Thereby, a favorable brand image is established. China's local enterprises account for a small proportion in the domestic market and lack competitiveness whereas famous foreign retail chain enterprises are relatively strong and have bigger scales. These retail chain enterprises went into China's first-tier cities, establish branches one after another to encroach on China's local enterprise's market shares. At present, the well-known foreign enterprises which have entered Beijing, Shanghai, and Guangzhou all have fine brand image and strong brand awareness. Examples of these enterprises are: Crocodile and Pierre Cardin from France, Playboy from the U.S., Puma from Germany, Wellcome, Parknshop, and China Resources from Hong Kong, Yaohan and General from Japan. It takes a long time to develop an excellent brand image. Compared with the flocks of foreign chain enterprises, China only has few popular chain enterprises. Because of development gap and the eagerness for quick success, China's chain enterprises ignore the brand development. Therefore, our chain enterprises did not have popular international brand like Carrefour and Wal-Mart.

\subsection{It is Hard to Form Economy of Scale with Shortage of Funds and Slow Construction of Stores}

The key to chain management is to gain profit by econo- my of scale. If there are only a few network portals and stores, then we are unable to achieve economies of scale by means of lowered costs and prices, which are acquired from centralized stocking and management. There are 9 unities in chain management: unified store names, unified store forms, unified shopping, unified prices, unified distribution, unified accounting, unified management, unified service, and unified promotion. More funds, which are unaffordable for newly-built enterprises, will be needed to establish chain enterprises which are incompatible with these 9 unities. It is difficult for these newly-built enterprises to form economy of scale due to the restriction of funds as well as store areas. Compared with big foreign enterprises, our local enterprises have less scale but higher management costs, thus making our local enterprises disadvantaged in the field of sales. This current situation will not be easily changed in a short-term (As shown from table 3).

\section{The Methods should be Taken for China's Chain Enterprises}

\subsection{To Enhance the Establishment of Distribution Center and Informatization}

As an important system in chain enterprises, an excellent logistics system plays an essential role in the success of chain enterprise management. In order to lower the costs to get low prices and purchasing costs, some chain enterprises blindly replenish their stock, which result in overstock and an increase of costs. The increase of costs, in turn, will undoubtedly weaken the enterprise's loss and profit ability, thus exerting the sales pressure. The distribution center of chain enterprises is acting like human's heart, which provides supplies constantly. Logistics system not only stresses the high efficiency of distribution, but also emphasizes the minimization of management costs. The combination of these two elements will optimize the logistics system. In our daily life, the adoption of unified purchasing, distribution and price will

Table 3. Top 5 China's Chain Enterprises in 2009

\begin{tabular}{ccccc}
\hline Year & $\begin{array}{c}\text { Numbers of } \\
\text { stores(unit) }\end{array}$ & $\begin{array}{c}\text { Business areas } \\
\text { (ten thousand square meters) }\end{array}$ & $\begin{array}{c}\text { Numbers of } \\
\text { employees } \\
\text { (ten thousand) }\end{array}$ & $\begin{array}{c}\text { Sales amount } \\
\text { (hundred million) }\end{array}$ \\
\hline 2004 & 77631 & 7202.6 & 128.20 & 8393.6 \\
2005 & 105684 & 8687.5 & 160.10 & 12587.8 \\
2006 & 128924 & 8979.0 & 187.10 & 14952.2 \\
2008 & 145366 & 10044.0 & 186.19 & 17754.3 \\
\hline
\end{tabular}


make chain enterprises to receive a higher price discounts, a reduced circulation fee and sales price. In this way, economy profit could be achieved. China's chain enterprises should grasp the current favorable chances to train skilled personnel in various ways, integrate the resources, regulate internal management, and choose the appropriate development and construction model, so as to expand our own distribution center gradually.

At present, the informatization construction of China's chain enterprises have achieved significant progress, however, development and improvement are yet to be further management. With the constant development of enterprises, the stock management, sale statistics, commodity categorization and so on all need the support of a powerful information system, which enables the rapid processing of complicated data, and display of the effective information. In this way, enterprises could enhance the management and obtain the necessary information. On the market, to get to know the information timely is essential. Therefore, international chain giant Wal-Mart made huge amount of funds at all costs to research the advanced information system.

Although China's enterprises cannot made investment like Wal-Mart do, they should pay attention to information construction, optimize and upgrade the information system constantly, with the purpose of facilitating and strengthen information construction.

\subsection{Enhancement of Large Scale and Collectivi- zation of Chain Enterprises}

It is an objective requirement to achieve large scale management and scale profits for further development of China's chain enterprises. If there are only a few stores of a chain enterprise, the market is not widely distributed. Also, logistics service capability is not being fully developed, thus resulting in idle resources. From the view of economy, it is waste to have idle resources, which will increase the cost for enterprise operation. Only when the numbers of stores meet a certain requirement and the market coverage is big enough, the whole system's management will be reasonably operated. This kind of operation is manifested as the shortened stock of goods and faster goods circulation. In this way, costs have been lowered effectively and the increase of enterprise's loss-and-win ability. Currently, we have quite a gap compared with the amounts of world's giant enterprises stores. Merger and acquisition are an important measure to expand the scale of enterprises. At first, by merger and acquisition, China's enterprises could integrate resources so as to broaden the scales themselves. Then, China's enterprises should widely develop franchise, and try various chain methods to occupy retail and service market. Therefore, there is a soaring of the numbers of stores and an effective and entire layout through distribution. Using this method, we could obtain the funds for the further development. Meanwhile, the increase of market distribution is beneficial to the enterprises-market cultivation, which is the base for the further development. At last, we should actively explore small towns and rural market, striving to develop chain supermarkets which are compatible with the consumption level of these residents. At present, due to the intense business competition in China's medium and large cities, chain enterprises could choose to develop in the vast rural market. Now it is a good opportunity for chain marketing in rural areas. With the rapid development of China's economy, the pace of rural area's urbanization is speeding up and the farmer's living standard is lifting. Many rural areas, especially the coastal rich provinces appear a great number of modern satellite cities and towns. These regions are thickly populated and have easy transportation, thus having a higher society development. The traditional retail industry can hardly meet their consumption needs. According to the consumption habits and preferences of the local residents, China's chain retail industry should actively explore the markets in these regions and research the market conditions in order to establish chain branch and expand sales scale.

\subsection{To Enhance the Chain Management Stand- ardization and Adopt Modern Management Measures: Do well upon Talent-training}

Due to their giant structure and large numbers of stores, the management of chain enterprises, especially those have multiple chain ways becomes complicated. The relationship among headquarter and the branches are complicated in these kinds of enterprises. Thus, a unified and effective management is impossible. China's chain enterprises should continue to improve the management system. To meet this goal, the headquarter and branches should have a clarified property right as well as a cleared relation, thus enabling the employees to work more actively both in headquarter and branches. In this way, the development of the enterprise could be facilitated and the competitiveness can be strengthened. Among human, productivity, and production relations, human is the most essential element. The level of employee's quality plays an important role in enterprises development. The quality of employees is the representative of an enterprise's brand image. In the contact with customers, the service attitude, professional skills and so on are criterion for customer's evaluation and the measurement of an enterprise. Therefore, good talent-training and increased employee's quality are both the significant methods for China's enterprise development.

\subsection{Establishment of a Good Enterprise's Brand Strategy}

Brand is an important and intangible asset for an enterprise, to whom, it stands for a potential competiveness and the profit capability. From the perceptual point of view, brand is a comprehensive image in vision and idea field of a commodity or an enterprise. It takes some time and process to build a good brand. By building a good business morality, China's chain enterprises should be strict and be careful in purchasing merchandise in order to ensure the merchandise quality. In no time should we make exorbitant profits to abandon business morality, thus destroying our brand. What we should always be persistent is to keep the fake and shoddy merchandises 
away from the market, protect the rights of customers and maintain both merchandise's quality and quantity.

A well-built brand will not show up if we do not spend long-term time on it. Once a brand is being widely accepted by customers, the enterprise will give customers a healthy, honest, and energetic image. Therefore, the enterprise will gain many profits. In order to implement brand strategy, the enterprise should at first know brand positioning. Today, with thousands of brands on market, how customers will get to know and have a clear idea of brand ourselves is related to brand positioning, which can effectively display the characteristic and key value of any product or service. For chain enterprises, brand positioning is about how to stand out and have unique traits within a large number of brands. Then, the chain enterprises need to implement the brand strategy to raise the brand image. The prerequisite of brand strategy implementation is to ensure the quality of any product or service. Only under the condition of good quality can chain enterprises win the trust of customers. Besides, effective promotion is also a vital part in brand strategy implementation. Every day, customers are surrounded by various kinds of advertisements, which overflow too much. Therefore, chain enterprises should choose reasonably advertisement and promotion measures to obtain the maximum profits. An excellent promotion and advertisement will, in a short time, to impress customers, who will be more brand-cognitive. At the same time, chain enterprises should select the most effective approach according to its own condition.

\subsection{Use International Chain Enterprise's Expe- riences As an Reference}

At present, China's chain retail industries are facing intense competition. Chinese and foreign retail enterprises are at a stage of confrontation. The advanced hardware facilities, excellent organization management ability, and efficient mature operation system put international retail industry in an apparently advantaged position. The organization and management of a great number of large-scale retail enterprises are making reformation and innovations. In order to face more intense competition and better adapt to the customer's needs, the world retail giant Wal-Mart and Carrefour are reducing the management hierarchy and separating the powers down. On one hand, the reduction of management hierarchy simplifies the structure, thus lowering the enterprise's operation costs. On the other hand, report of information from common employees to higher authority will become easier. In Wal-Mart's organization structure, CEO only sets 4 departments: shopping plaza, Sam's club, international business, and distribution service. Except for these 4 departments there come vast branches below. The separation of powers in management is an innovative practice for international chain enterprises. Separation of powers means the higher administrators give some management rights and decision-making power to subordinates and share together. The benefit of separation of powers is obvious. Not only the employees will work with more passion, they will be encouraged thus working harder in the future. In this way, customer's needs will be met better and increase the work efficiency. International chain enterprises also emphasize the enterprise's culture construction. Enterprise culture, which is formed in the long-term operations by employees in different ranks, is the sum of commonly accepted value, group awareness, style of work, behavior standards, and ways of thought. An excellent enterprise culture enables the enthusiasms of employees, increase the connection and competition, thus making employees to actively preserve the enterprise's reputation and profit. The completion of a well-built enterprise culture needs the common efforts of all employees in a very long time.

\section{Conclusions}

The development of chain management has a significant impact to innovation and reformation of China's business operation methods, strengthening the reformation of enterprise circulation, promotion of circulation management system, thorough change of operation system, reasonable and ordered competition condition, industry modernization, and the increase of national macro regulation. Under the context of fierce competition and rapid market's changes, China's chain enterprises should, first, eager to learn, draw lessons and experiences, and utilize strategy thought to formulate a whole development plan and brand strategy. Second, China's enterprises should adapt to the new conditions in a positive way, explore new markets and raise the service quality and informatization levels.

\section{References}

[1] Xiangqian Sun. The Development of Chain Management and the Enhancement of Agriculture, Rural Areas, and Farmersthe Current Situation, Existing Problems, Strategy and Suggestions of Ningxia Collective Enterprises [J]. Newspaper of South-Central University for Ethnic Communities (Humanistic and Social Sciences Edition) 2003, S2:131-132.

[2] Hongguang Peng. The Discussion of Electronic Business's Chain Management Logistics System [J]. Business Research, 2005, 20:203-206.

[3] Yanrun Zhang. The View of Management and Training of Employees in Chain Enterprises [J]. Modern Finance-Tianjin Finance College Newspaper, 2003, 08:59-62.

[4] Sun Yunxin, Huang Peiqing. The Website Location Model and Hereditary Calculation of Competitive Chain Management Network [J]. Science and Science and Technology Management 2001, 10:60-63.

[5] Taitian Mao, Yingwu Chen. Regional Logistics Center Location Model of Chain Management Based on Gravity. [J]. Industrial Engineering, 2008, 03:123-126.

[6] Karen Smith. Chain Store Age [M].Business \& Law Press 2003

[7] Sarah Wilson. Sales \& Marketing Management [M].2006.

[8] Abraham White. Chain Store \& Consumers [M]. Electronic Industry Press, 2005. 